\title{
Influence of Microstructure and Experimental Parameters on Mechanical and Wear Properties of Al-TiC Surface Composite by FSP Route
}

\author{
S. Jerome*, S. Govind Bhalchandra, S.P. Kumaresh Babu, B. Ravisankar \\ Department of Metallurgical and Materials Engineering, National Institute of Technology, \\ Tiruchirappalli - 620 015, Tamilnadu, India \\ *Corresponding Author: jerome_sa@rediffmail.com,
}

\begin{abstract}
Surface properties decide the fatigue, wear and corrosion behavior of a material. Hence their performance can be improved by surface modifications. Friction Stir Processing (FSP) is a promising technique to develop surface composite. The aim of the present study is to develop defect free surface composite of Al 5083 alloy reinforced with TiC particles and investigate the particle distribution in the matrix, mechanical properties and wear behavior of the composites. Microstructural observations were carried out by using optical and scanning electron microscopy (SEM). The microstructural studies revealed that distribution of particles were more uniform in samples subjected to double pass than the single pass FSP. The microhardness profiles along top surface and across the cross section of the processed samples were evaluated. The average hardness along the top surface was found to increase by $27.27 \%$, as compared to that of the base metal $(88 \mathrm{Hv})$. The particles were incorporated maximum average depth about $250 \mu \mathrm{m}$ in the surface composite. The slurry erosion tests revealed that the wear rate was highly reduced in case of double pass FSP samples as compared to base metal and single pass FSPed composite.
\end{abstract}

Keywords: Al- TiC surface composite, Friction stir processing, Microhardness, Wear resistance.

\section{INTRODUCTION}

Properties like high strength, elastic modulus, and improved resistance to wear, fatigue and creep of metal-matrix composites reinforced with hard ceramic phases, make them promising structural materials for aerospace and automobile industries compared to unreinforced metals. However, 
due to the incorporation of non-deformable ceramic phases, these metal-matrix composites also suffer a great loss in ductility and toughness, which limits their wide range of applications to a certain extent. For wear resistance applications, life of the components can be improved by surface modification with ceramic phases. This concept results in the development of surface composite, where the surface layer of the alloys alone is reinforced with ceramic phases while the bulk of components retain their original composition and structure with higher toughness.

The various surface modification techniques to fabricate surface metal-matrix composites include high-energy laser melt treatment, high-energy electron beam irradiation, plasma spraying, powder metallurgy and casting. But in all these existing techniques, it is hard to avoid interfacial reactions and the formation of detrimental phases. Moreover, as these techniques involves liquid phase processing at elevated temperatures, critical control over the processing parameters is essential to get ideal solidified microstructure in the surface layer, which makes their use further difficult. To avoid the above mentioned problems, the process should carry out at a temperature below the melting point of the substrate as did in solid phase surface modification techniques. There are several solid phase surface modification techniques are available which include diffusion bonding, co- extrusion, Friction Stir Processing etc. In this study, Friction Stir Processing (FSP) developed by R.S Mishra et.al [1], was attempted to incorporate ceramic particles into the surface of aluminum alloy to fabricate surface composite.

R.S. Mishra et. al. [1] had developed the first Al- SiC surface composite synthesized by FSP route and obtained a composite layer ranged from 50 to $200 \mathrm{~mm}$. The SiC particles are distributed on the aluminum matrix and particles have excellent bonding with the aluminum alloy substrate. The microhardness of the surface composite was increased almost two times greater than the substrate. Morisada et. al. [2-4] had developed magnesium based surface composites by incorporating different particles such as $\mathrm{SiC}$, fullerene and multi walled carbon nano tubes and reported that the properties of surface composites were better than monolithic alloys. Wei Wang et.al. [5] had extended the same concept to fabricate bulk composite. Al$\mathrm{Al}_{2} \mathrm{O}_{3}$ nano surface composite was developed by Shafiei - Zarghani [6] and A.P. Gerlich et. al. [7] had developed multi walled CNT reinforced composite by the same route. Based on the limited available literature, the research work had been mainly focused on the development of the composite and few studies were focused to understand the effects of process parameters on the mechanical properties of the composites. In the present work, microstructural studies for the top and cross- sections had been carried out to analyze the particle distribution in a surface composite developed by FSP. Mechanical properties mainly on hardness and wear studies in corrosive environment also evaluated.

\section{EXPERIMENTAL PROCEDURES}


Friction Stir Processing was used for the development of surface composite of aluminium 5083 alloy reinforced with TiC particles. A cold rolled and stabilized plate of aluminium 5083 alloy was used as the substrate. The chemical composition of the alloy is as shown in Table 1.

Table.1. Chemical Composition of the Aluminum 5083 Alloy

\begin{tabular}{cccccccccccc}
\hline Element & $\mathrm{Si}$ & $\mathrm{Fe}$ & $\mathrm{Zn}$ & $\mathrm{Mg}$ & $\mathrm{Ti}$ & $\mathrm{V}$ & $\mathrm{Ni}$ & $\mathrm{Mn}$ & $\mathrm{Cr}$ & $\mathrm{Bi}$ & $\mathrm{Al}$ \\
\hline Wt (\%) & 0.124 & 0.296 & 0.064 & 4.715 & 0.006 & 0.002 & 0.019 & 0.756 & 0.215 & 0.09 & Rest \\
\hline
\end{tabular}

Samples with the dimensions of $150 \mathrm{~mm} \times 100 \mathrm{~mm} \times 6 \mathrm{~mm}$ thick plates were used for processing. The average particle size of $\mathrm{TiC}$ particle used was 4 to $10 \mu \mathrm{m}$. The samples were subjected to single and double pass of FSP with and without TiC particles under different conditions. A cylindrical FSP tool made of EN 31 steel was used for FSP (hardened to 64 HRc) and its dimensions are listed in the Table 2. The processing parameters used in this study are listed in the Table 3.

Table.2. Tool details

\begin{tabular}{ll}
\hline Material & EN 31, quenched \& tempered condition \\
\hline Shoulder & $\varnothing 18 \mathrm{~mm}$, Concave shoulder, $3^{\circ}$ included angle \\
\hline Pin & $\varnothing 6 \mathrm{~mm}$, pin length: $2 \mathrm{~mm}$, left handed thread \\
\hline
\end{tabular}

Table 3. Process parameters used for the FSP with TiC powder

\begin{tabular}{cccc}
\hline $\begin{array}{c}\text { Trial } \\
\text { No. }\end{array}$ & $\begin{array}{c}\text { Tool Rotation Speed } \\
\text { (r.p.m.) }\end{array}$ & $\begin{array}{c}\text { Traverse Speed } \\
\text { (mm/min) }\end{array}$ & Visual Observations \\
\hline 1 & 1400 & 16 & No defect, smooth surface \\
\hline 2 & 1120 & 16 & No defect, smooth surface \\
\hline 3 & 900 & 16 & No defect, smooth surface \\
\hline 4 & 710 & 16 & No defect, smooth surface \\
\hline
\end{tabular}

Particle distributions were observed at the cross, traverse and top section of the processed sample. Hitachi scanning electron microscopy was used for particle distribution observation. The Zwick Vickers hardness tester was used for the hardness survey of the processed sample using $300 \mathrm{gm}$ of load with15 seconds of dwell time. Phase analysis was carried out by XRD (Rigaku Corporation, Japan, D/MAX ULTIMA II, $3 \mathrm{~kW}, \mathrm{Cu} \mathrm{K} \alpha$ ). Wear resistance of the base plate and the composites were studied by performing pot erosion wear tests. These tests were performed for base metal, single pass and double pass FSP with TiC particles. The size of the samples used was $20 \mathrm{~mm}$ x $20 \mathrm{~mm}$ and the sand particle size was $80 \mu \mathrm{m}$. The slurry concentration of $25 \%$ and 
50\% was prepared and erosion rates were performed at 500 and 900 r.p.m. The weight loss for each specimen measured after $1 \mathrm{hr}$ of the test. The total test duration for each sample was conducted for 4 hrs. The marine environment was simulated by using $3.5 \%$ brine solution during the wear test.

\section{RESULTS AND DISCUSSIONS}

\subsection{Microstructural Observations}

FSP was carried out using the parameters shown in the Table 3. Visibly defect free composites were fabricated in all passes. Meager flash and a smooth surface over the FSPed region were obtained. Metallographs of the cross sections of the samples taken perpendicular to the direction of tool travel revealed that the particle distribution improved with the higher tool rotational speed.

From the figure 1a it was observed that for the tool rotation of 710 r.p.m. TiC particles could not be mixed well with the $\mathrm{Al}$ matrix and were found either in the form of small lumps below a thin layer of $\mathrm{Al}$ or in the form of clusters. This can be attributed to the low heat input associated with lower rotational speed that induces insufficient material flow. With the rotational speed increased to 900 r.p.m. and 1200 r.p.m. the thin layer on the top of the $\mathrm{TiC}$ particles was sheared by the trailing shoulder over the undisturbed TiC particles present in the grooves (Figure $1 \mathrm{~b}$ and $1 \mathrm{c}$ respectively). Compaction was ensured by the plunge force which was accentuated by the trailing edge due to rake angle effect. It can be observed in the figure $1 \mathrm{~d}$ that as the rotational speed was increased to 1400 the particle distribution was improved. The metallographs revealed that the TiC particle tend to originate from the groove (that acts as a source) and then spreads towards the surface where they are mixed with Al by the shearing action of the shoulder. The layer of $\mathrm{Al}$ above the $\mathrm{TiC}$ particles reduced considerably with increasing rotational speed and was replaced by the surface composites when the rotational speed of 1400 r.p.m. was used.

The etched specimen shown in Figure 2 helped to understand how the shoulder-driven flow has resulted in the formation of surface composites along with grain refinement due to dynamic recrystalisation of the plasticized material. On getting the surface composites on the base plate an attempt was made to homogenize the $\mathrm{TiC}$ particles in the surface composite by performing multipass FSP. A second FSP pass was taken over the first pass in two different methods i) the tool traverse was in the same direction as those of the first pass and ii) in a direction opposite to the first pass. $100 \%$ overlap was made over the first pass in both the cases as shown in Figure 3. 

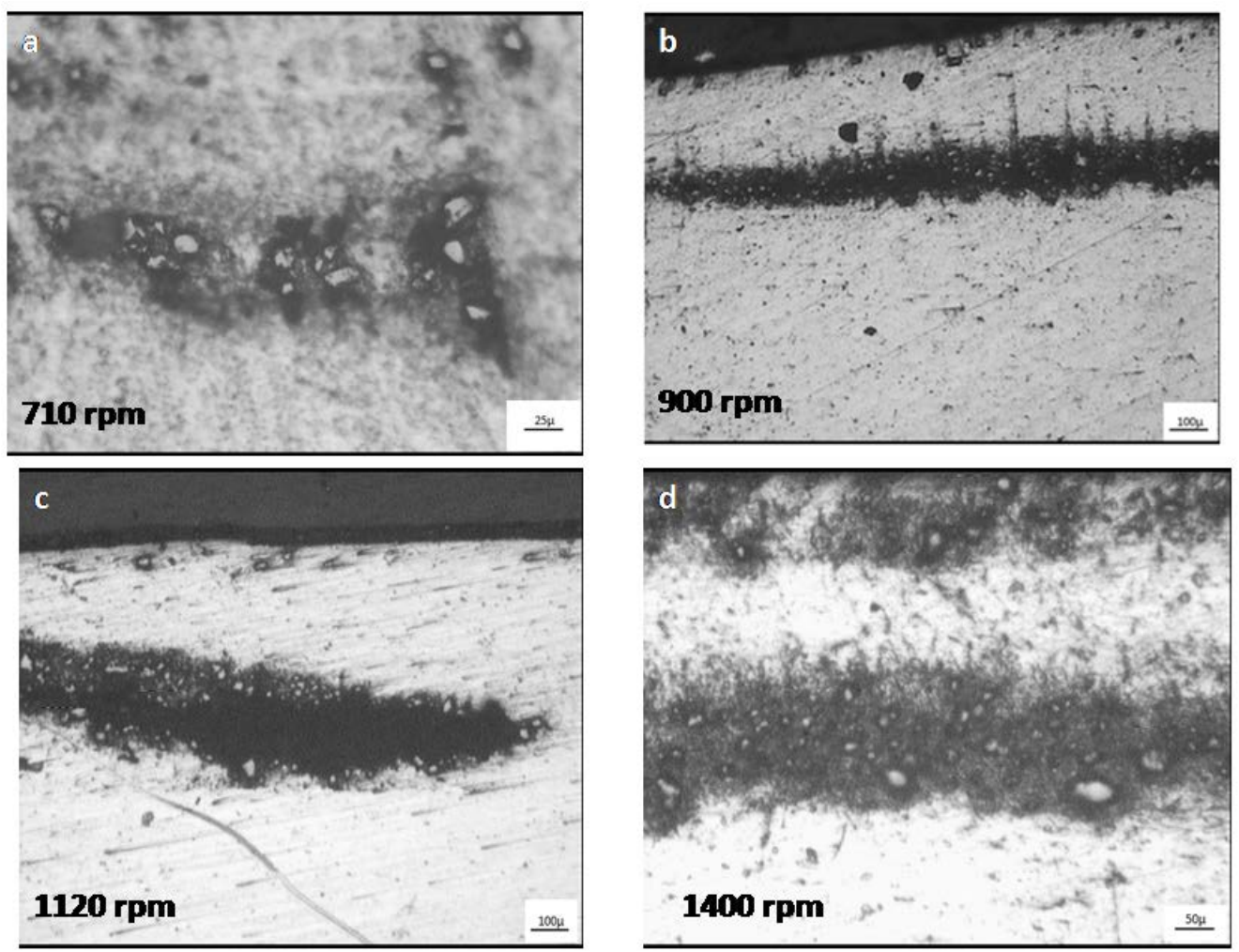

Figure 1. Microstructures of unetched specimens showing particle distribution after single pass FSP along the cross section for rotational speed of a) 710 , b) 900, c)1120 and d)1400 r.p.m.

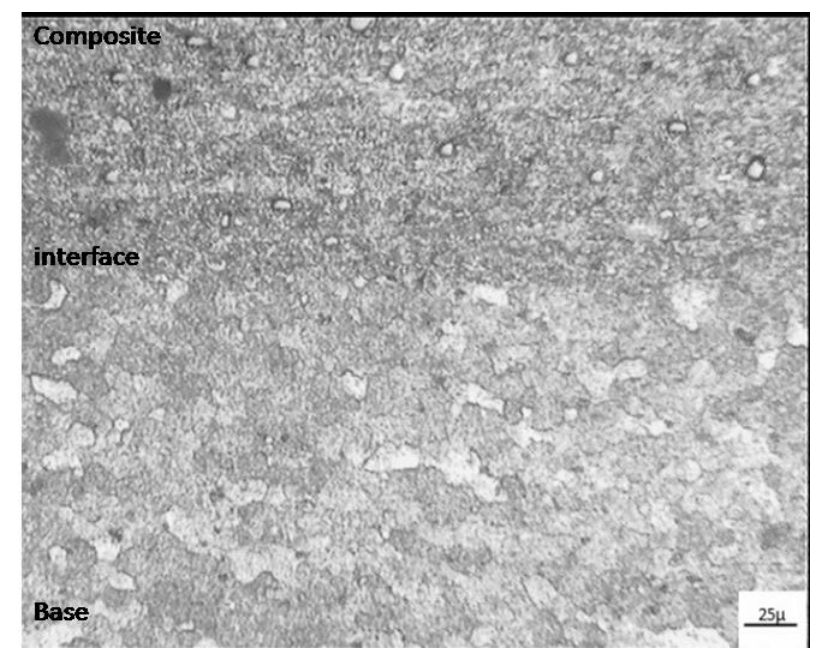

Figure 2 Microstructure of etched specimen of Al-TiC composites

The parameters for the second pass were the same as those of the first pass. All the trials yielded defect free composites with nominal flash. Microstructural characterization revealed that the particle distribution was improved invariably in both the cases of double pass. However, double pass FSP made in the direction opposite to the first pass showed more uniform distribution. SEM 
images shown in figure 3 revealed that in the case of double pass in the same direction, particles were not uniformly distributed throughout the region of the surface composite layer. In the latter case, uniform layer of surface composite was seen over major portion of the FSPed region. This can be attributed to the fact that AS of the second pass overlapped on the RS of the first pass resulting in homogenization of the FSP region and the surface composites contained in it. The SEM images of the cross section of these specimens proved this fact.
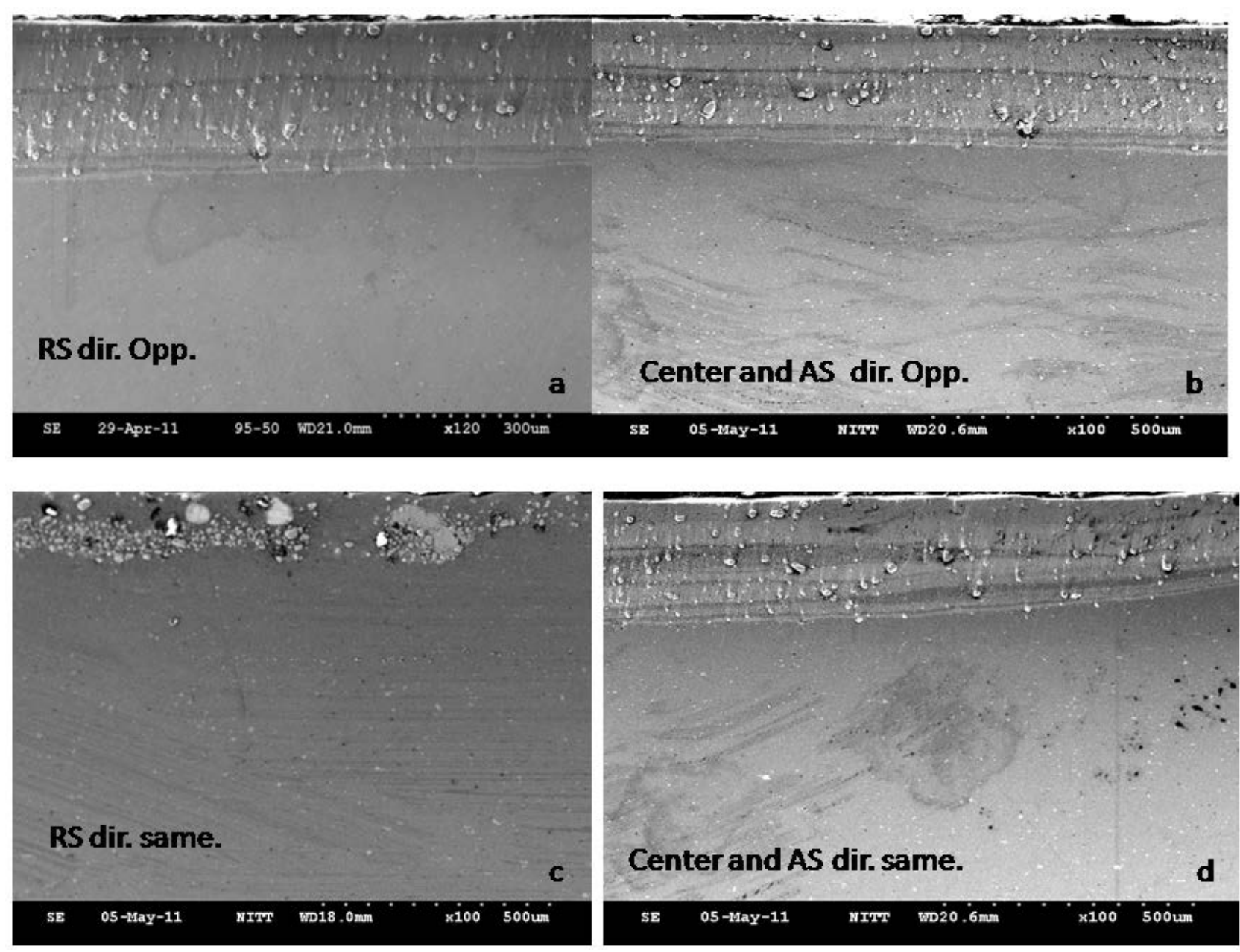

Figure 3 SEM images of cross section of double pass FSPed specimen a \& b) Opposite direction, c \&d ) same direction

\subsection{Microhardness Details}

The base metal microhardness was observed to be $88 \mathrm{Hv}$ and it is shown in figure 4 . Variation in maximum hardness values with the parameters like rotary speed for a feed rate of $16 \mathrm{~mm} / \mathrm{min}$ have been displayed in the same figure. From the figure 5 it was observed that the hardness values of the single pass FSP samples shown the maximum hardness values were achieved at 
1400 r.p.m. These results are in consensus with the results obtained through microstructural changes obtained after FSP and addition of TiC. Also, M. Raaft et al [9] revealed that, increasing the tool rotational speed increases the hardness of the composite layers. It is because of the fact that $\mathrm{Al} 5083$ is strain hardenable alloy. Thus, owing to increased flowability at higher heat input imparted by higher rotational speeds, strain hardening effect contributes to the increased hardness. It is clear that, in FSP, as the rotational speed increases, the heat input also increases. However, it has been reported that the calculated maximum temperatures are nearly the same in all the rotational speeds. This phenomenon can be explained by the following two reasons: first, the coefficient of friction decreases when a local melt occurs; secondly, the latent heat absorbs some heat input.

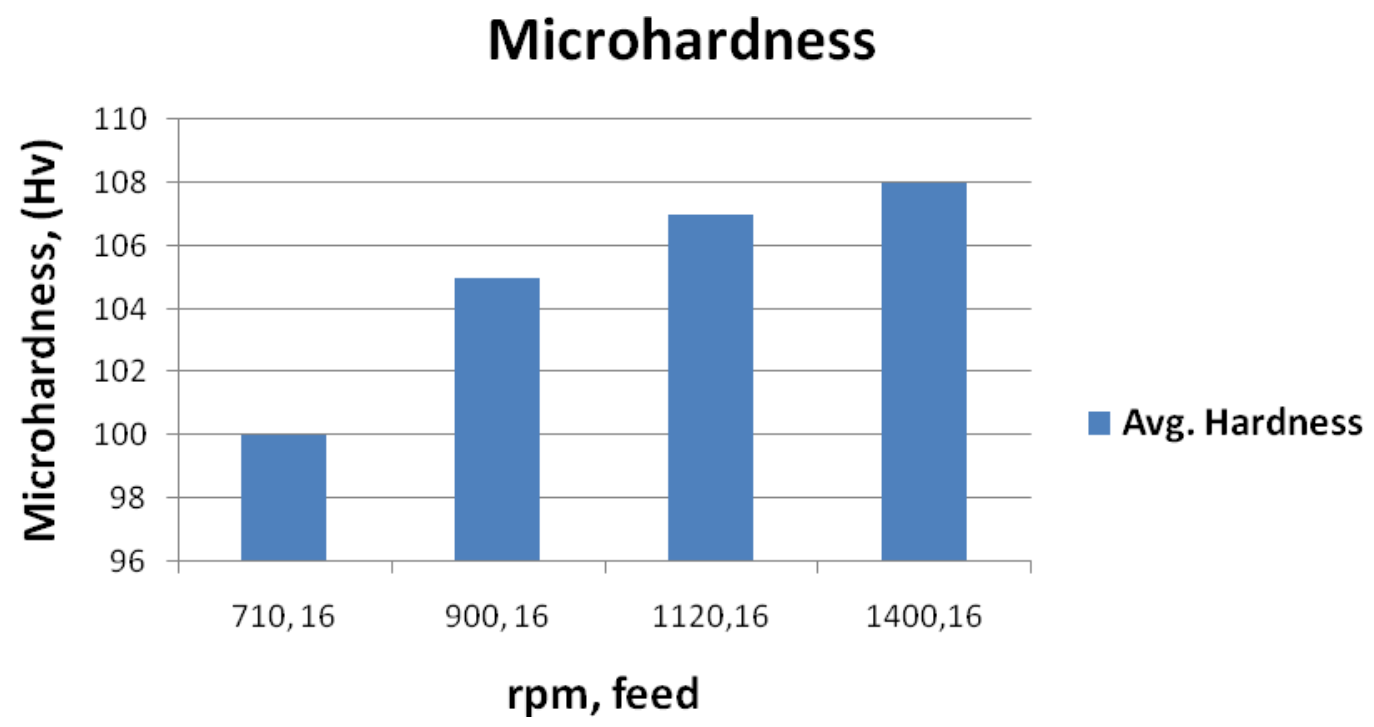

Figure. 4 Variation in Average hardness values with the rotary speed and given feed rate of the tool during FSP using concave shouldered tool

In these cases, the hardness was measured and plotted at equal intervals from the advancing side (AS). From the figure 5 it was observed that, the hardness would be more at the advancing side as compared to the retreating side (RS). Also the hardness within the stir zone would be more or less uniform. As many of the researchers reported, grain refinement is due to dynamic recrystallization and mechanical stirring. Also it was reported that the grain size is even finer at the AS than that at the SZ and RS. Hence, for samples without TiC particles, the Hall-pitch hardening takes and an increase in hardness takes place in the processed zone. Also it was expected that the hardness in the AS would be more, as the material is transferred from the RS to the AS, and the same is forged against the advancing side base material. Although the increase in hardness is mainly due to the grain refinement (Hall-Petch Strengthening) in case of Al 5083, dispersion strengthening is reported to contribute to a larger extent. FSPed samples without TiC powder, whereas the presence of $\mathrm{TiC}$ powder contributes much to the hardness in case of the 
surface composite. The grain size would be even finer as TiC particles prevent the grains to grow by providing a large number of nucleation sites.
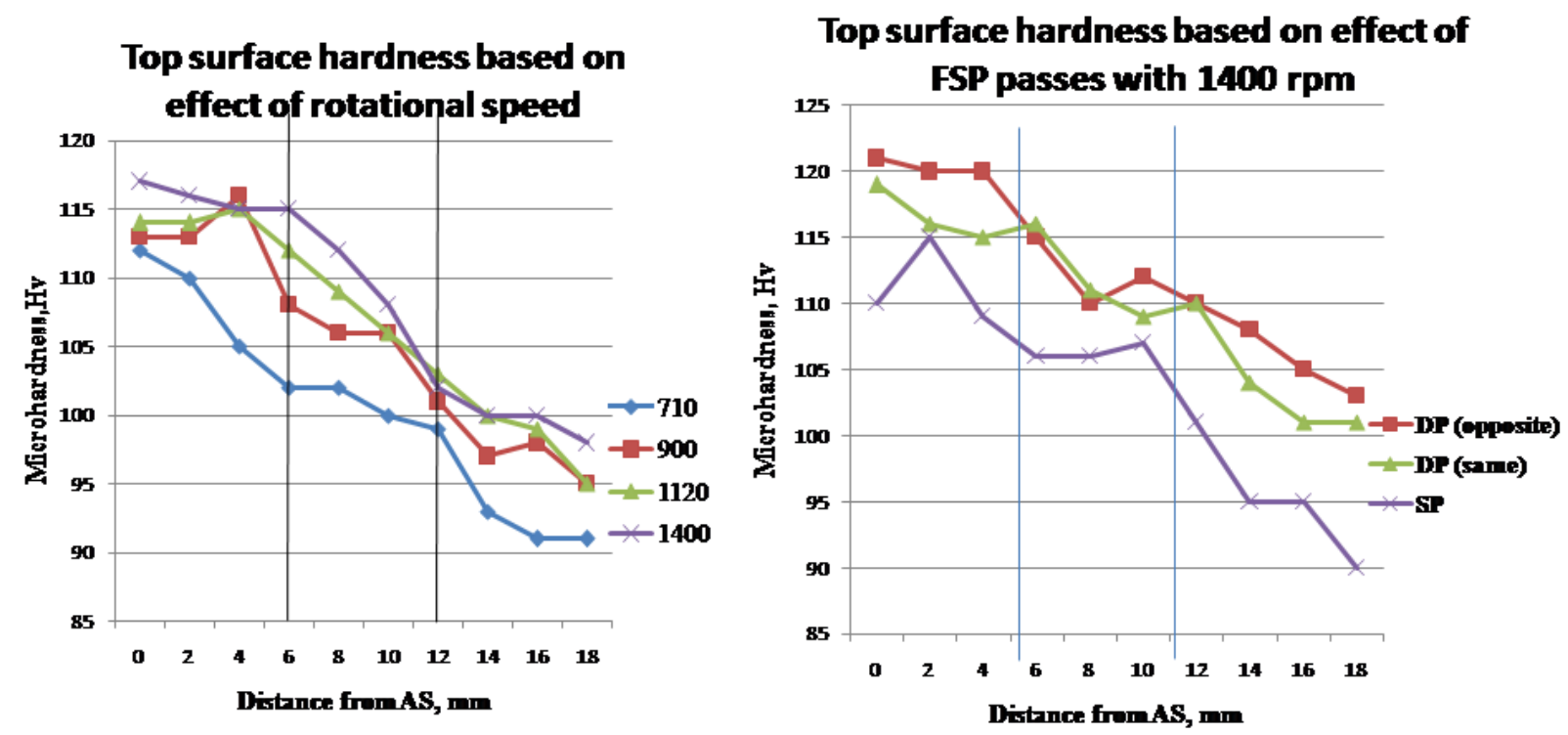

Figure. 5 Variation in the hardness values with the rotatioanl speed and effect of FSP passes at $1400 \mathrm{rpm}$

Rotational speed appears to be the most significant process variable since it also tends to influence the translational velocity. Higher tool rotational speed resulted in a higher temperature and slower cooling rate in the FSP zone. Lower heat input condition due to lower rotational speed resulted in lack of stirring resulting in less improvement in hardness. It was observed that the hardness values were invariably higher for surface composites than those of the base metal. This increase can be attributed to the presence of hard $\mathrm{TiC}$ particles in the $\mathrm{Al}$ matrix along with the grain refinement effect of FSP.

In the present study, in case of surface composite developed by single pass FSP with groove design, the average hardness along the top surface was found to increase by $22.72 \%$ as compared to that of the base metal whereas the in case of surface composite developed by double pass FSP in same and opposite direction, the average hardness along the top surface was found to increase by $25 \%$ and $27.27 \%$ respectively, as compared to that of the base metal.

It is already known that the presence of external particles reduces the flowability of the base metal in the FSP zone. This is the major hurdle in formation of defect free surface composites. It is very well known that it is the frictional heat produced by the shoulder that results in plasticising the material below shoulder and around the pin. In the presence of extended pin the effect of stirring action of the shoulder at the pin end fades as the length of the pin increases. 
This is due to the fact that the pin rotation is insufficient to drive the material from the RS to the AS of the tool pin. It finally results in what is called as channel/worm/groove defect. This defect increases as pin length increases for given set of parameters. Thus it can be inferred that the shoulder driven flow influences the pin driven flow when the pin is short and hence results in defect free passes. Tool geometry also plays a vital role in defect formation. In the present case the concave shoulder helps to contain the plastic material within it and thus prevents to some extent the loss of material from the stir zone due to flash formation. So also as the length of the pin increases the amount of metal extruded from the plate also increases. In a case when the shoulder is not able to contain this material excessive flash formation can be seen. In the present study, the tool design successfully averted problems associated with reduced flowability of TiC particles, flash formation and defect formation and the use of rake angle helped inclusion of particles in the stir zone to form surface composites.

\subsection{XRD Analysis}

a
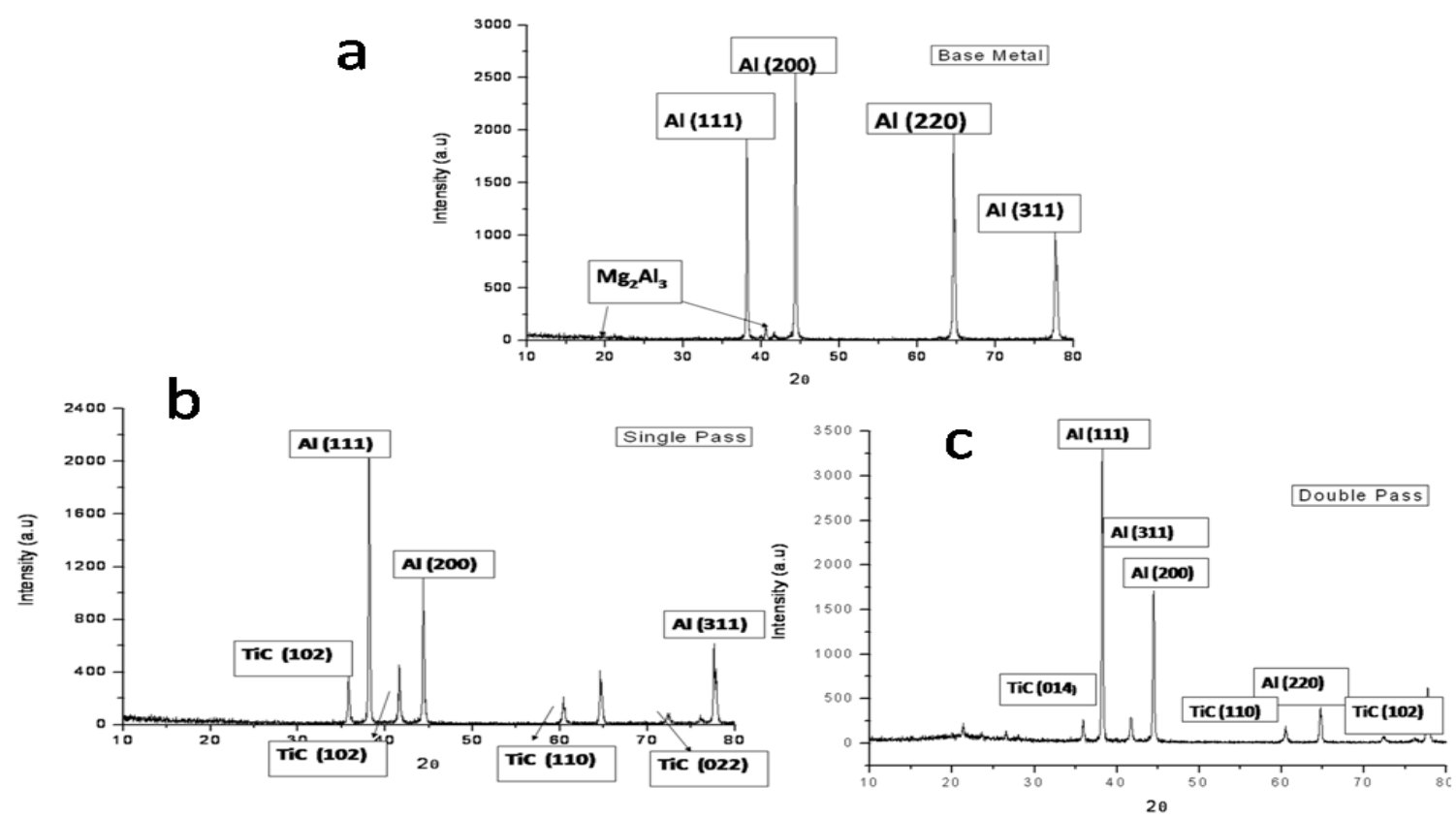

Figure 6. XRD of a) base, b) single pass FSP and c) double pass FSP

Figures 6 a-c showed the XRD pattern of the base metal and the surface composites. The presence of TiC peaks confirmed that the particles were successfully incorporated in the $\mathrm{Al}$ matrix but there were no detrimental phases or other intermetallics revealed by the XRD. Because, during FSP, the plate temperature could be reached above the recrstallisation temperature of the matrix and not exceeding the melting point of both the matrix and the reinforcement particles [10] and the retention time at this particular temperature also less hence, no interfacial reaction could be happened between the particles with the matrix. From these 
results, it is confirmed that the surface composite developed by the FSP method is proved to be a clean and better than the other processing routes but the uniform distribution of the particles could be obtained only by increasing the number of FSP passes.

\subsection{Wear Studies}

The FSPed specimens were subjected to Pot Erosion Test shown in Figure 7 with four different set of conditions as tabulated in Table 4. Slurry was prepared at neutral $(\mathrm{pH} 7)$ brine solution of $3.5 \%$. The percentage weight loss measured after every one hour has been plotted for every specimen for the experiments mentioned above.

Table 4. Experimental conditions for Pot Erosion Test

\begin{tabular}{ccccc}
\hline Experiment no. & $\mathbf{1}$ & $\mathbf{2}$ & $\mathbf{3}$ & $\mathbf{4}$ \\
\hline R.P.M. & 500 & 900 & 500 & 900 \\
\hline Slurry Concentration (\%) & 25 & 25 & 50 & 50 \\
\hline
\end{tabular}

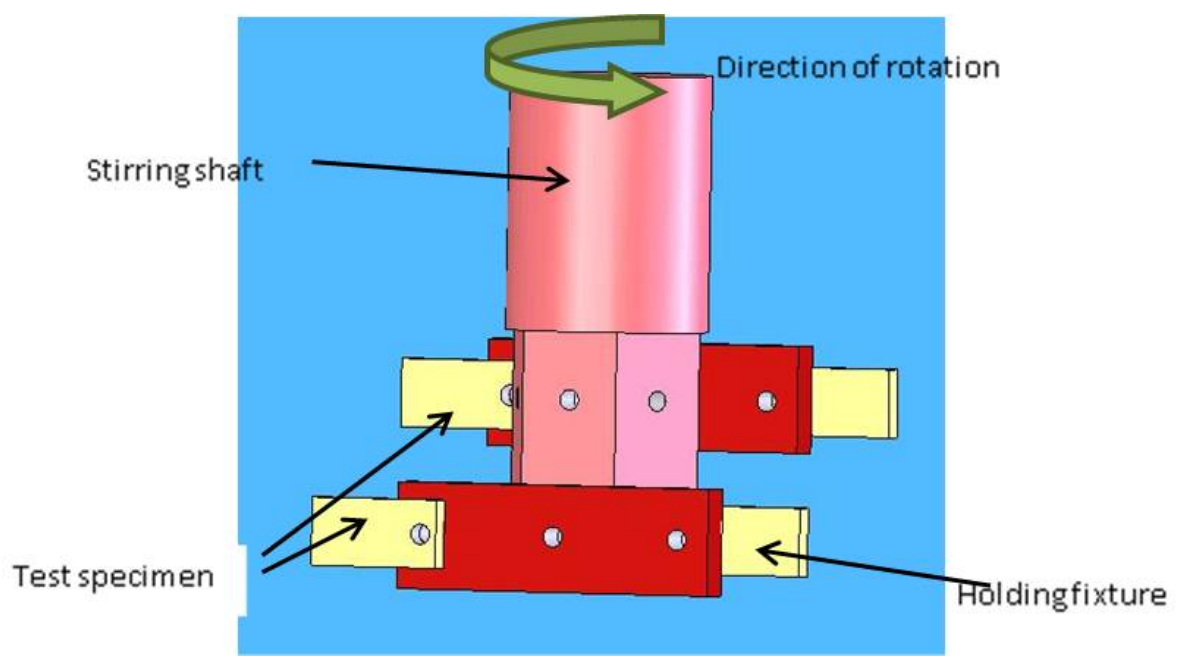

Figure 7. Pot erosion Test setup

From the results shown in figure 8 it can be concluded that the weight loss due to erosive wear was more when the r.p.m. and the slurry concentration were higher. Interestingly for each experimental condition the wear resistance is increased from base metal to single pass FSP to double pass FSPed sample. These results confirm the increase in hardness in surface composites improves its wear resistance as compared to base metal. Experimental data and corresponding graphs have been shown in Figure 8.

It can be seen that initial wear rate of SP is lesser and it increases with time. This is due to the fact that the initial wear resistance is provided by the surface composites. With time as this layers 
wears out the wear resistance is still provided by the grain refined FSPed material. The double pass FSPed composite sample shows persistent resistance to wear.

Expt 1: 500 rpm 25\% Conc.

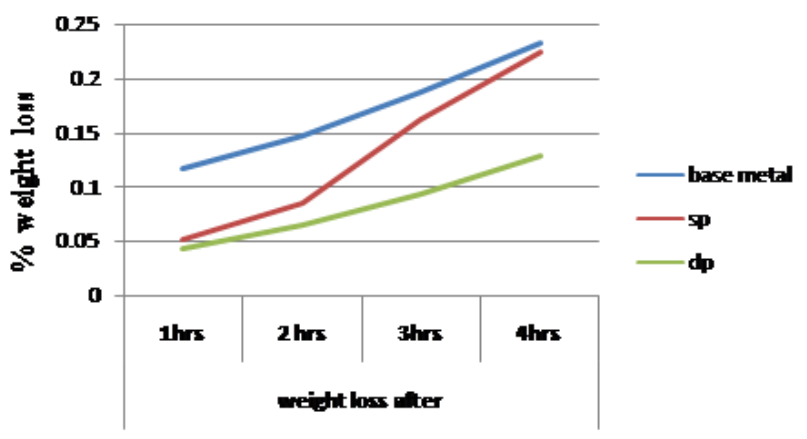

Expt $3-500$ rpm $50 \%$ conc.

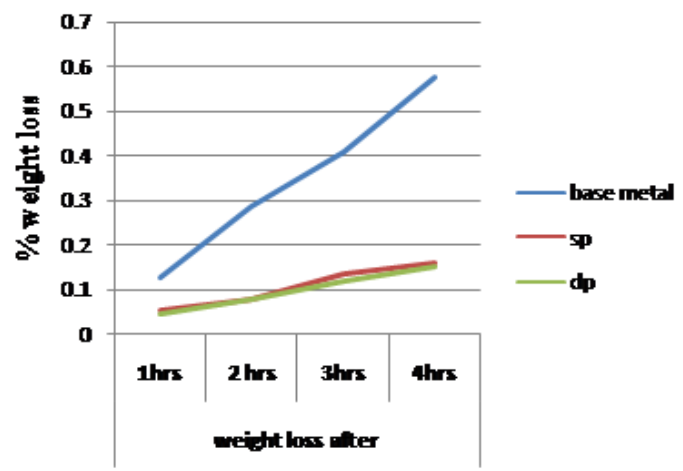

Exp 2-900 rpm 50\%conc.

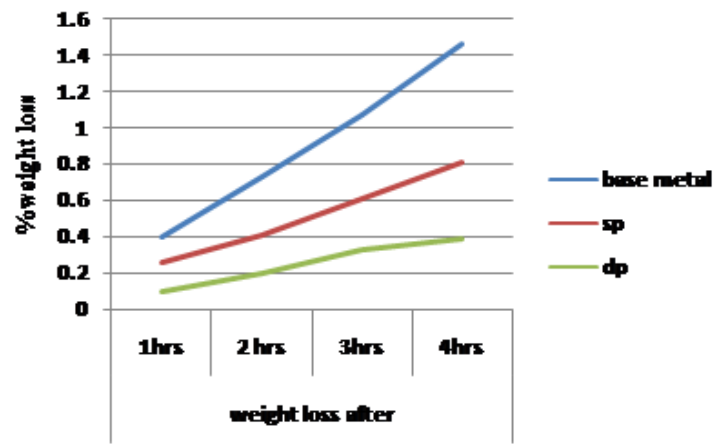

Expt 4-900 rpm 50\% conc.

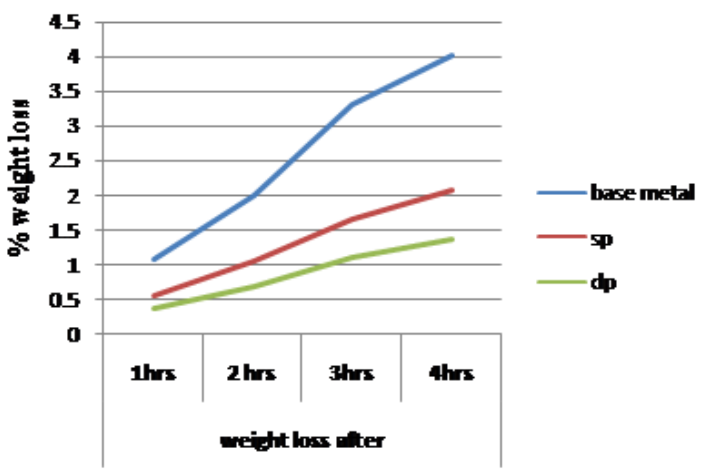

Figure 8. Wear rate of base metal and Al-TiC composites by single and double pass FSP

\subsubsection{Effect of speed}

Erosive/abrasive attack is a function of the energy of the impinging particle and the severity of attack increases with energy. The energy of the impinging particle is directly proportional to the speed in line with the kinetic energy of the impinging particles $\left(1 / 2 \mathrm{mv}^{2}\right)$. Thus, the wear rates increased as the speed was increased from 500 to $900 \mathrm{rpm}$ irrespective of the material. However, at higher speeds, say $900 \mathrm{rpm}$, the mobility of sand particles is decreased and hence they do not have enough time to make an effective impact and they simply slide off instead of making any sensible impact. Further at such high speeds the chances of intercollisions amongst the erodent particles are more. Additionally the chances of rebounding of erodent particles are also high at such speeds. All these factors cumulatively reduced the wear rates at $900 \mathrm{rpm}$.

\subsubsection{Effect of concentration}

Increasing the sand content simply increases the severity of erosive/abrasive attack because a greater number of particles are impinging on the surface. On the other hand, the severity of 
corrosive attack may decrease because the effective volume of the corrodant decreases. It is observed that the $\mathrm{pH}$ of the solution normally approached towards neutral value, when the sand content was varied indicating decrease in the basicity of the corrodant. In the present study the wear rates increased on increasing the sand content in marine solutions irrespective of the material in spite of decrease in the corrosivity of the medium. Further, at normal impact, material Losses due to abrasion are minimal and thus erosion is the most dominant mode of material removal. So, by increasing sand concentration the wear rate is increased irrespective of material and it is shown in Figure 9.

\section{Effect of Parameters on Wear rate}

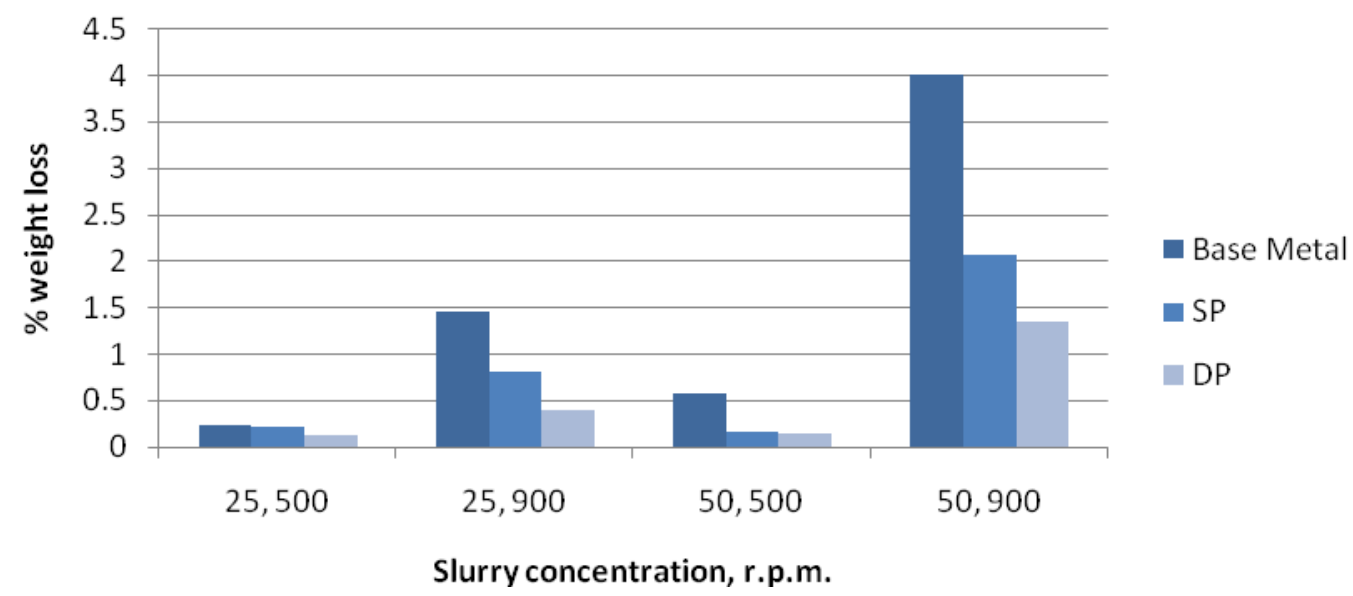

Figure 9. Effects of experimental conditions on wear rate

\subsubsection{Effect of reinforcement}

From the Figures 8 and 9 it is observed that the composites have shown higher wear resistance than the base material because, these reinforced $\mathrm{TiC}$ particles protect the matrix by providing a kind of shadowing effect. Further, the presence of TiC particles reduced the effective metallic area exposed to the corrosion solution and thus reduced the extent of corrosive attack on the matrix. These factors cumulatively improved the wear resistance of composite. Along with TiC particles, after every FSP passes the refined grain structure were obtained and hardness also increased due to strain hardening effect which is also improves the wear resistance of the composites. Further corrosive attack is reduced because the effective metallic area exposed to the corrosive media is reduced to a greater extent [11]. Thus, the Al-TiC surface composite exhibited greatest wear resistance than the base material tested.

Figure 9 compares the wear rate of the materials considered during the four different experiments and shows the comparative wear rates during these experiments. From the figure the experimental conditions can be arranged in the ascending order of wear rate as follows:

$$
\text { Expt } 1<\text { Expt } 3<\text { Expt } 2<<\text { Expt } 4
$$



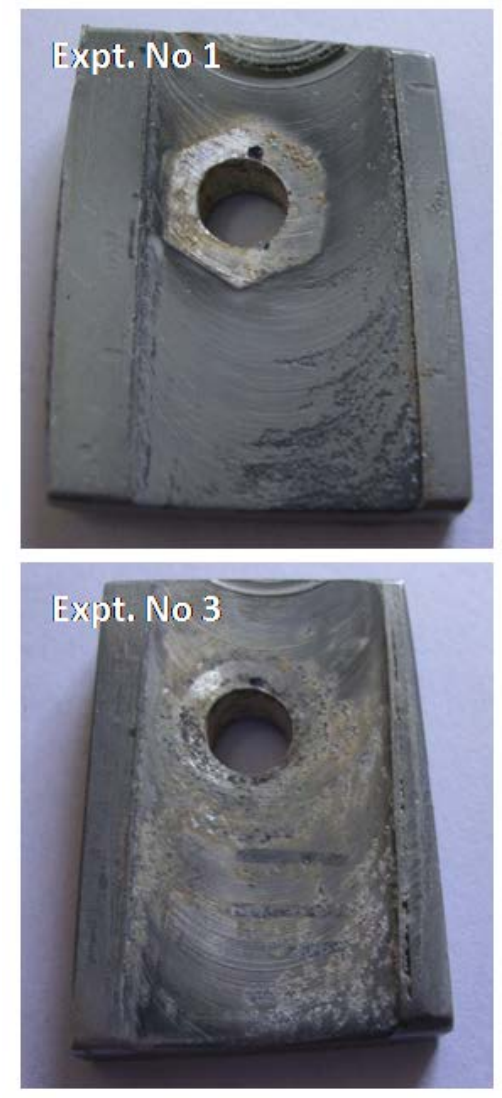
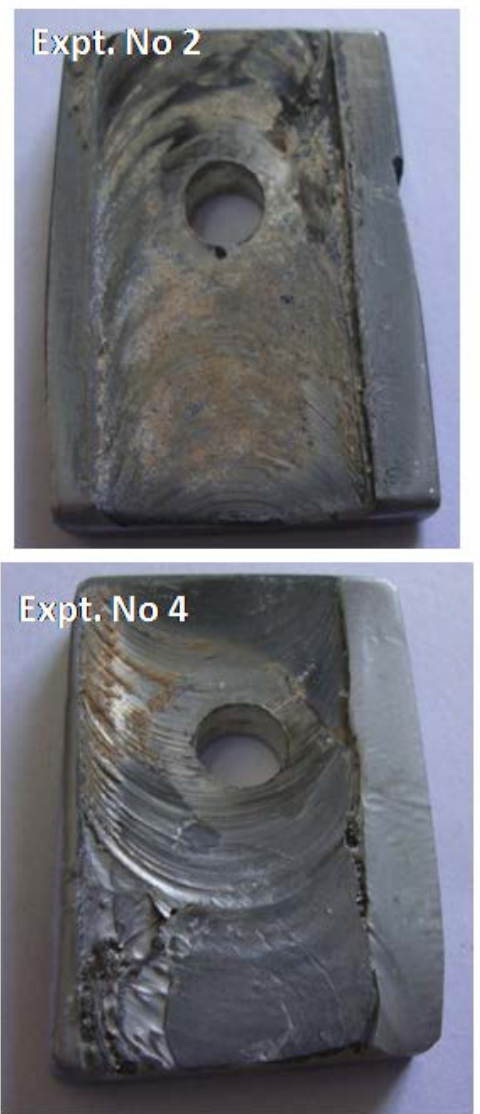

Figure 10. Wear specimens of double pass FSPed samples for a) Expt. 1, b) Expt. 2, c) Expt. 3 and d) Expt. 4

Figure 10 shows the effect of speed and sand concentration of the wear of the Al-TiC surface composites fabricated by double pass FSP. In general, the wear rate was quite low for all the cases owing to small particle size. Aluminum is highly ductile material and in the present case wear is due to both particle impacts at high velocity as well as abrasion. In particular, high velocity impact resulted in deformation wear when higher r.p.m. (900) was used for both the values of slurry concentration. Thus r.p.m had more influence than slurry concentration. Noticeably, high values of wear were seen in Expt 4 due to the higher collision efficiency resulting from higher slurry concentration.

\section{CONCLUSIONS}

From the present study the following conclusions were drawn:

i. In the present study particle distribution during development of surface composites by FSP of Al 5083 was studied. Defect free composites were achieved in all FSP passes. Based on the microstructural observations it was found that the distribution of particles 
was noticeable in AS and SZ. Double pass in opposite direction resulted in more uniform distribution of particles.

ii. Surface composite developed by single pass FSP with groove design, the average hardness along the top surface was found to increase by $22.72 \%$ as compared to that of the base metal whereas the in case of surface composite developed by double pass FSP in same and opposite direction, the average hardness along the top surface was found to increase by $25 \%$ and $27.27 \%$ respectively, as compared to that of the base metal. The maximum average depth of surface composite was found to be $250 \mu \mathrm{m}$ in hole-design.

iii. The weight loss due to erosive wear was more when the r.p.m. and the slurry concentration were higher. For each experimental condition the wear resistance is increased from base metal to single pass FSP to double pass FSPed sample. These results confirm the increase in hardness in surface composites improves its wear resistance than the base metal.

\section{ACKNOWLEDGEMENT}

The authors wish to acknowledge Naval Research Board, Government of India (DNRD/05/4003/NRB/172) for supporting this research work.

\section{REFERENCES}

[1] R.S. Mishra , Z.Y. Ma, I. Charit, "Friction stir processing: a novel technique for fabrication of surface Composite", J. Materials Science and Engineering A, 341, pp 307-310, (2003)

[2] Y. Morisada , H. Fujii , T. Nagaoka , M. Fukusumi, "Effect of friction stir processing with SiC particles on microstructure and hardness of AZ31", J. Materials Science and Engineering A, 433, pp 50-54, (2006)

[3] Y. Morisada, H. Fujii, T. Nagaoka , K. Nogi, M. Fukusumi, "Fullerene/A5083 composites fabricated by material flow during friction stir processing", J. Composites: Part A, 38, pp 2097-2101,(2007)

[4] Yoshiaki Morisada, Hidetoshi Fujii, Tadashi Mizuno, Genryu Abe, Toru Nagaoka, Masao Fukusumi, "Modification of thermally sprayed cemented carbide layer by friction stir processing", J. Surface \& Coatings Technology, 204, pp 2459-2464, (2010).

[5] Wei Wang, Qing-yu Shi, Peng Liu, Hong-ke Li, Ting Li, "A novel way to produce bulk SiCp reinforced aluminum metal matrix composites by friction stir processing", $J$. Materials processing technology, 209, pp 2099-2103, (2009).

[6] A. Shafiei-Zarghani, S.F. Kashani-Bozorg, A. Zarei-Hanzaki, "Microstructures and mechanical properties of $\mathrm{Al} / \mathrm{Al}_{2} \mathrm{O}_{3}$ surface nano-composite layer produced by friction stir processing", J. Materials Science and Engineering A 500, pp 84-91, (2009). 
[7] D.K. Lima, T. Shibayanagib, A.P. Gerlich, "Synthesis of multi-walled CNT reinforced aluminium alloy composite via friction stir processing", J. Materials Science and Engineering A, 507, pp 194-199, (2009).

[8] M. Raaft, T.S. Mahmoud, H.M. Zakaria, T.A. Khalifa, "Microstructural, Mechanical and wear behaviour of A390/graphite and $\mathrm{A} 390 / \mathrm{Al}_{2} \mathrm{O}_{3}$ surface composites fabricated using FSP", J. Materials Science and Engineering A,(2009.)

[9] H.N.B. Schmidt, T.L. Dickerson, J.H. Hattel, "Material flow in butt friction stir welds in AA2024-T3", J. Acta Materialia, 54, pp1199-1209, (2006).

[10] Y.L. Saraswathi, S. Das, D.P. Mondal, "Influence of microstructure and experimental parameters on the erosion-corrosion behavior of Al alloy composites", J.Materials Science and Engineering A 425, pp 244-254, (2006). 